\title{
Influência de metodologias de inoculação de Macrophomina phaseolina no desempenho de cultivares de soja
}

\author{
Giovana Carolina Dourado Cruciol ${ }^{1} \&$ Maria Luiza Nunes Costa ${ }^{2}$
}

${ }^{1}$ Departamento de Proteção vegetal, Universidade Estadual Paulista "Julio de Mesquita Filho", Rua José Barbosa de Barros, n¹780, CEP: 18.610.307, Botucatu-SP; ${ }^{2}$ Universidade Federal de Mato Grosso do Sul - Chapadão do Sul-MS.

Autor para correspondência: Giovana Carolina Dourado Cruciol (giovanacruciol@hotmail.com)

Data de chegada: 05/05/2016. Aceito para publicação em: 13/07/2017.

$10.1590 / 0100-5405 / 2185$

\section{RESUMO}

Cruciol, G.C.D.; Costa, M.L.N. Influência de metodologias de inoculação de Macrophomina phaseolina no desempenho de cultivares de soja. Summa Phytopathologica, v.44, n.1, p.32-37, 2018.

A podridão de carvão causada pelo fungo Macrophomina phaseolina é uma das principais doenças que causa podridões no sistema radicular e caule das plantas de soja, e sua ocorrência vem aumentando a cada safra. Com isso objetivou-se avaliar a influência de metodologias de inoculação de $M$. phaseolina no desempenho de cultivares de soja. O experimento foi conduzido em delineamento inteiramente casualizado, em parcelas sub-subdivididas no tempo, contendo duas cultivares de soja (NA 7337 RR e CD 2737 RR), seis métodos de inoculação (semente não inoculada, semente inoculada por 48 horas, semente inoculada por 72 horas, infestação do solo com três grãos de arroz, infestação do solo com seis grãos de arroz e infestação do solo com nove grãos de arroz) e 3 períodos de avaliações (20, 40 e 60 dias após a semeadura) com 6 repetições. As avaliações foram realizadas medindo-se a altura de plantas, diâmetro do colo, número de folhas, comprimento e largura de folhas e incidência do fungo Macrophomina phaseolina. Os resultados dos experimentos indicaram que o método de inoculação utilizando grãos de arroz inoculado com o fungo M. phaseolina proporcionou maiores prejuízos à cultivar NA 7337 RR, porém a cultivar CD 2737 RR foi influenciada pelo método de inoculação diretamente na semente de soja. A cultivar NA 7337 RR demostrou ser mais tolerante ao fungo Macrophomina phaseolina. Nos períodos de avaliações os parâmetros de quantificação indireta da doença evoluíram progressivamente aos 20, 40 e 60 dias. Observou-se também que apenas o tratamento testemunha não apresentou o fungo M. phaseolina e todos os métodos de inoculação empregados proporcionaram o desenvolvimento do fungo nas plantas de soja. Todos os métodos de inoculação utilizados foram eficientes na inoculação de M. phaseolina em soja. O método de inoculação diretamente na semente por 48 e 72 horas, desenvolveu sintomas precoces.

Palavras-chave: métodos de inoculação; patógeno; Glycine max; podridão de carvão

\section{ABSTRACT}

Cruciol, G.C.D.; Costa, M.L.N. Influence of Macrophomina phaseolina inoculation methodologies on the performance of soybean cultivars. Summa Phytopathologica, v.44, n.1, p.32-37, 2018.

Charcoal rot caused by the fungus Macrophomina phaseolina is one of the major diseases that causes rot in the root system and stem of soybean plants, and its occurrence has increased at every harvest season. The aim of this study was to evaluate the influence of $M$. phaseolina inoculation methodologies on the performance of soybean cultivars. The experiment was conducted in a completely randomized design, in sub-subdivided plots, containing two soybean cultivars (NA 7337 RR and CD 2737 RR), six inoculation methods (non-inoculated seed, seed inoculated for 48 hours, seed inoculated for 72 hours, soil infestation with three rice grains, soil infestation with six rice grains and soil infestation with nine rice grains) and three evaluation periods (20, 40 and 60 days after sowing) with 6 replicates. Evaluations were performed by measuring the height of plants, diameter of the colon, number of leaves, length and width of leaves and incidence of the fungus Macrophomina phaseolina. Results of the experiments indicated that the inoculation method using rice grains inoculated with the fungus M. phaseolina provided greater damage to the cultivar NA 7337 RR, but the cultivar CD 2737 RR was influenced by the method of inoculating directly in the soybean seed. The cultivar NA 7337 RR showed to be more tolerant to the fungus Macrophomina phaseolina. In the evaluation periods, the indirect quantification parameters of the disease progressively evolved at 20, 40 and 60 days. Only control treatment did not present the fungus M. phaseolina and all employed inoculation methods provided the development of the fungus in soybean plants. All inoculation methods were efficient in inoculating $M$. phaseolina in soybean plants. The method of directly inoculating in the seed for 48 and 72 hours developed early symptoms

Keywords: Inoculation methods; pathogen; Glycine max; charcoal rot

A incidência de doenças na cultura da soja vem aumentando a cada safra no Brasil. Este fato é decorrente do aumento de área cultivada no país, pois a soja é a cultura de maior importância para a economia do mundo e novas fronteiras agrícolas estão sendo abertas. Outro fator é o sistema de monocultura empregado em algumas regiões, que possibilita a permanência do hospedeiro na lavoura e o patógeno se desenvolve originando a doença. A resistência de fungos a produtos químicos também é de grande relevância, decorrente ao uso inadequado dos fungicidas o número de patógenos resistentes esta tomando uma grande proporção (2).

A podridão de carvão é uma doença de sistema radicular comum na cultura da soja, principalmente em lavouras onde não se faz o preparo do solo adequado, o solo permanece compactado e dificulta a penetração das raízes ocorrendo o seu desenvolvimento superficial (1). 
As condições propícias para o desenvolvimento do fungo M. phaseolina são temperaturas entre $28-35^{\circ} \mathrm{C}$, ocorrendo danos maiores em clima seco e altas temperaturas. Este patógeno sobrevive no solo e em restos culturais, é transmitido por sementes (3 e 11).

O fungo M. phaseolina é considerado um dos mais predominantes em infecções radiculares de soja no Brasil (24). Na safra 1996/97 as perdas ocasionadas por M. phaseolina na cultura da soja reduziram 900 mil toneladas de grãos no Brasil (20). O uso de cultivares resistente é classificado como a medida mais prática e econômica para controlar a podridão de carvão, no entanto, há poucos estudos sobre.

Machado (17) avaliou a resistência de dez cultivares de soja à $M$. phaseolina, selecionando as cultivares Vicoja e Santa Rosa como as menos suscetíveis, Coker 102 apresentou reação intermediaria e Cocker 338 a mais suscetível. Mengistu et al. (19) publicaram resultados de cultivares de soja com níveis de resistência a $M$. phaseolina, sendo eles PI594302, PI567562A, PI506764 e PI567334, contudo 93\% dos acessos avaliados mostraram-se moderadamente suscetíveis e relatam a necessidade de se realizar novos estudos com acessos soja no Brasil.

Dada à importância da podridão de carvão das raízes na cultura da soja, e não se ter estudos avaliando metodologias de inoculação de $M$. phaseolina na cultura da soja, neste ensaio foi desenvolvido metodologias de inoculação que constitui importante ferramenta para o estudo de resistência e manejo da doença.

Lima et al. (14) avaliaram a inoculação natural, utilizando sementes de crotalária colonizadas com M. phaseolina, e depositaram as mesmas no solo, ocorrendo assim a podridão cinzenta do caule em feijãocaupi. Falcão et al. (7) utilizaram grãos de milho e arroz colonizados com Sclerotinia sclerotiorum e Sclerotium rolfsii, para possível contaminação no solo e, posteriormente, realizaram a semeadura da soja, que também apresentou os sintomas da doença. Medeiros et al. (18) avaliaram dois métodos de inoculação (areno-orgânico e palito de dente) de Rhizoctonia solani e Macrophomina phaseolina em meloeiro, sendo o método do palito de dente mais eficiente. Claudino (5) pesquisaram métodos de inoculação artificial e natural de Macrophomina phaseolina em mamoneira. O método do palito de madeira apresentou o menor comprimento da lesão, diferindo dos métodos do grão de arroz e disco cultura, os quais não diferiram entre si. Sousa (23), testou métodos de inoculação artificial de Macrophomina sp. em plantas de feijãofava observando que inoculação do grão de arroz infestado, e disco de micélio foram eficientes na inoculação artificial de M. phaseolina.

A inoculação é o processo pelo qual o inóculo de fitopatógenos é transferido do local onde é produzido para o local no hospedeiro onde vai infectar. Existem dois métodos de inoculação, o artificial e o natural. O método de inoculação artificial possui desvantagens, pois não simula o que ocorre naturalmente na lavoura, porém se obtém uma resposta mais rápida. Sendo realizado através de ferimentos na planta ou mesmo infestação artificial do solo com o patógeno. Entretanto, a inoculação natural simula o que ocorre em campo, um exemplo é a infestação de substratos ou sementes contaminados com o patógeno (5).

Devido à importância da podridão de carvão das raízes na cultura da soja, objetivou-se neste trabalho avaliar a influência de metodologias de inoculação de M. phaseolina no desempenho de cultivares de soja.

\section{MATERIAL E MÉTODOS}

O trabalho foi desenvolvido no Laboratório de Fitossanidade e casa de vegetação da área experimental da Universidade Estadual de Mato Grosso do Sul (UEMS), na Unidade Universitária de Cassilândia (UUC).
O experimento foi conduzido em delineamento inteiramente casualizado, em parcelas sub-subdivididas no tempo, contendo duas cultivares de soja (NA 7337 RR e CD 2737 RR), seis métodos de inoculação (semente sem inoculação, semente inoculada por 48 horas, semente inoculada por 72 horas, inoculação do fungo com três grãos de arroz, inoculação do fungo com seis grãos de arroz e inoculação do fungo com nove grãos de arroz) e 3 períodos de avaliações (20, 40 e 60 dias após a semeadura) com 6 repetições. Para emergência total foram utilizadas duas cultivares de soja e seis métodos de inoculação com 6 repetições.

Para o cultivo do patógeno foram utilizados erlenmeyers com arroz sem casca, previamente umedecidos com água $(100 \mathrm{~mL}$ de água/ 50 $\mathrm{g}$ de arroz) por dez minutos, a água foi removida e posteriormente esterilizados em autoclave por vinte minutos a $120^{\circ} \mathrm{C}$. Após o resfriamento do arroz, foram adicionados 20 discos miceliais de 3 $\mathrm{mm}$ provenientes de culturas puras do fungo e incubados em BOD (demanda bioquímica de oxigênio) por um período de dez dias, a $28^{\circ} \mathrm{C}$, sob fotoperíodo de 12 horas e umidade $70 \% \pm 10$ para a multiplicação do fungo. Logo após a adição dos discos sobre o arroz, os frascos eram agitados diariamente para obter uma colonização mais rápida $\mathrm{e}$ uniforme. Posteriormente, os grãos de arroz foram depositados no solo dos vasos a uma profundidade de um centímetro, correspondentes a cada método de inoculação.

A inoculação do fungo M. phaseolina nas sementes de soja foi realizada pelo método de restrição hídrica, sendo o fungo cultivado em meio BDA acrescido de manitol, no potencial hídrico de -1,0 MPa $(73,77 \mathrm{~g}$ de manitol $)(6,15)$. Após o preparo do meio de cultura BDA (batata dextrose ágar), foi feita a repicagem do fungo através de discos miceliais e incubados em BOD por um período de sete dias, a $28^{\circ} \mathrm{C}$, sob fotoperíodo de 12 horas até que a colônia fúngica atingisse as bordas da placa de Petri. Em seguida foram depositadas as sementes de soja sobre o meio de cultura, para que ocorresse a colonização do patógeno nas mesmas. Ambos os cultivares de soja permaneceram em contato com o fungo por 48 e 72 horas, período correspondente a cada método de inoculação.

Em casa de vegetação, as sementes de soja foram semeadas em vasos de cinco litros, preenchidos com solo arenoso de barranco, retirado de uma área não cultivada, snedo este esterilizado em autoclave por uma hora em temperatura de $120^{\circ} \mathrm{C}$.

As avaliações foram realizadas aos 20, 40 e 60 dias após a semeadura, avaliou-se de acordo com Câmara e Heiffeig (4), altura de plantas, diâmetro do colo, número de folhas, comprimento e largura de folhas. Aos 60 dias a incidência do fungo Macrophomina phaseolina foi verificada da seguinte forma: foi retirada as plantas, lavadas em água corrente, e secas em temperatura ambiente. Com auxílio de um bisturi foram retirados pequenos fragmentos de caule e raiz, posteriormente foi feita a assepsia com hipoclorito $(0,5 \%)$ por um minuto, água esterilizada e secos em papel toalha também esterilizado. Logo, os fragmentos foram colocados em meio de cultura BDA contendo antibiótico estreptomicina e acondicionados em BOD a temperatura de $23^{\circ} \mathrm{C}$, fotoperíodo de 12 horas por 7 dias e umidade de $70 \% \pm 10$. Após este período foram preparadas lâminas com o crescimento fúngico verificado ao redor dos fragmentos plaqueados e observadas as estruturas em microscópio ótico, confirmando a presença de $M$. phaseolina.

Após a obtenção dos dados foi feita a análise estatística e o teste de médias Tukey, a 1 e a $5 \%$ de probabilidade e teste t para cultivares. Os dados de emergência de plantas foram transformados utilizando o software SISVAR (8). 


\section{RESULTADOS E DISCUSSÃO}

Os dados de análise de variância das avaliações realizadas no experimento encontram-se na tabela 1 .

Comparando as duas cultivares de soja, observou-se que a altura de plantas e diâmetro do colo da cultivar NA7337 RR apresentou valores menores que a cultivar CD 2737 RR com a inoculação de seis e nove grãos de arroz (Tabela 2)

A altura de plantas da cultivar CD 2737 RR não foi influenciada pelos métodos de inoculação aplicados, mas para a cultivar NA 7337 RR, nove grãos não diferiu de seis grãos e apresentaram altura inferior aos demais tratamentos (Tabela 2).

A cultivar NA 7337 RR apresentou menor diâmetro do colo na presença de nove grãos de arroz, diferindo dos demais tratamentos. A cultivar CD 2737 RR teve seu diâmetro do colo reduzido quando utilizou-se sementes inoculadas por 48 e 72 horas, diferindo apenas do tratamento com seis grãos de arroz (Tabela 2).

Pires \& Beserra Junior (22) testou a patogenicidade de $M$. phaseolina em feijão-fava utilizando três métodos de inoculação (disco de micélio, grão de arroz infestado e palito de madeira infestado). E observaram que disco de micélio e arroz infestado foram eficazes na indução de sintomas nas plantas de feijão-fava.

Na cultura da mamoneira, Claudino (5) utilizou três diferentes métodos de inoculação artificial e um método natural para o fungo $M$. phaseolina. Quanto à inoculação natural de M. phaseolina por meio da infestação artificial do substrato de cultivo, foi observado efeito negativo do genótipo, do tratamento da semente, e da concentração do inóculo sobre o diâmetro do caule e altura da planta.
Estudando-se diferentes métodos de inoculação para avaliar cultivares de soja na presença de Fusarium tucumaniae, Franco et al. (9), observaram que plantas testemunhas apresentaram altura superior a plantas inoculadas pelo método de grãos de sorgo e grãos de aveia, indicando que a infecção das plantas por $F$. tucumaniae foi efetiva e provocou paralização ou redução drástica no desenvolvimento das plantas.

Verificou-se interação entre períodos de avaliações e os métodos de inoculação com o fungo $M$. phaseolina, para altura de plantas. De modo geral, os valores de altura de plantas foram crescentes, 20 dias seguido por 40 dias e 60 dias em que as plantas de soja apresentaram maior altura (Tabela 3).

Aos 20 dias a altura de plantas não foi influenciada pelos métodos de inoculação. Já aos 40 dias o menor valor foi proporcionado por nove grãos de arroz, semelhante ao de seis e três grãos. Aos 60 dias nove grãos de arroz também reduziram a altura de plantas de soja, que diferiu apenas da testemunha e sementes inoculados por 48 horas (Tabela 3).

Da mesma forma que ocorreu interação entre períodos e métodos de inoculação para a variável altura, observou que o diâmetro do colo também foi crescente, 20 dias seguido por 40 e 60 dias (Tabela 4).

Aos 20 dias, o diâmetro do colo foi menor quando utilizado a inoculação por 72 horas, que diferiu apenas da inoculação com seis grãos de arroz. Entretanto, aos 40 dias o menor valor deste parâmetro foi proporcionado por nove grãos de arroz, que foi semelhante às sementes inoculadas por 72 horas. Aos 60 dias, nove grãos de arroz também reduziu o diâmetro do colo (Tabela 4).

De acordo com o trabalho realizado por Gava (10), a redução do diâmetro do colo de plantas de soja está diretamente relacionado com o

Tabela 1. Resumo da análise de variância para altura, diâmetro do colo, número de folhas, largura de folhas, comprimento de folhas de plantas de soja em função de cultivares, período de avaliações e métodos de inoculação. UEMS Cassilândia (MS), 2015.

\begin{tabular}{|c|c|c|c|c|c|}
\hline$\overline{\text { FV }}$ & Altura & Diâmetro do colo & Número de folhas & Largura de folhas & Comprimento de folhas \\
\hline Cultivar (C) & $3,07^{*}$ & $1,37^{*}$ & $3,68^{*}$ & $25,63^{\mathrm{NS}}$ & $0,03^{* *}$ \\
\hline Período (P) & $0,00^{* *}$ & $0,00^{* *}$ & $0,00^{* *}$ & $0,00^{* *}$ & $0,00^{* * *}$ \\
\hline $\mathrm{C} \times \mathrm{P}$ & $5,80^{\mathrm{NS}}$ & $2,10^{*}$ & $1,43^{*}$ & $2,00^{*}$ & $2,03^{*}$ \\
\hline $\mathrm{C} \times \mathrm{M}$ & $0,00^{* *}$ & $0,00^{* *}$ & $6,24^{\mathrm{NS}}$ & $0,01^{* *}$ & $0,00^{* *}$ \\
\hline
\end{tabular}

*** Significativo a $1 \%$ de probabilidade; "Significativo a $5 \%$ de probabilidade ${ }^{\text {N.S. }}$ não significativo

Tabela 2. Desdobramento da análise de variância para altura de plantas e diâmetro do colo em função de cultivares de soja e métodos de inoculação. UEMS Cassilândia (MS), 2015.

\begin{tabular}{|c|c|c|c|c|c|c|c|c|}
\hline \multirow[b]{2}{*}{ Métodos de inoculação } & \multicolumn{8}{|c|}{ Cultivares } \\
\hline & \multicolumn{2}{|c|}{ NA 7337 RR } & \multicolumn{2}{|c|}{ CD $2737 \mathrm{RR}$} & \multicolumn{2}{|c|}{ NA 7337 RR } & \multicolumn{2}{|c|}{ CD $2737 \mathrm{RR}$} \\
\hline & \multicolumn{4}{|c|}{ Altura (cm) } & \multicolumn{4}{|c|}{ Diâmetro do colo $(\mathrm{mm})$} \\
\hline Testemunha & 29,8 & A a & 23,81 & $\mathrm{~B}$ a & 2,98 & A a & 2,65 & $\mathrm{~B}$ ab \\
\hline Semente $48 \mathrm{~h}$ & 29,70 & A a & 19,00 & $\mathrm{~B}$ a & 3,10 & A a & 2,31 & B b \\
\hline Sementes $72 \mathrm{~h}$ & 25,61 & $\mathrm{~A} a \mathrm{~b}$ & 21,74 & $\mathrm{~B}$ a & 2,68 & A a & 2,37 & B b \\
\hline 3 grãos de arroz & 23,22 & A b c & 18,68 & $\mathrm{~B}$ a & 2,93 & $\mathrm{~A}$ a & 2,50 & $\mathrm{~B}$ a b \\
\hline 9 grãos de arroz & 15,51 & $B d$ & 23,48 & $\mathrm{~A}$ a & 2,01 & $\mathrm{~B} \quad \mathrm{~b}$ & 2,49 & $\mathrm{~A} a \mathrm{~b}$ \\
\hline C.V.(\%) & \multicolumn{2}{|c|}{38,82} & \multicolumn{2}{|c|}{32,00} & & & \multicolumn{2}{|c|}{26,23} \\
\hline
\end{tabular}

Médias seguidas de letras minúsculas diferentes na coluna e maiúsculas diferentes na linha para cada variável, diferem estatisticamente entre si pelo teste de Tukey a $5 \%$ de probabilidade para o fator métodos de inoculação e pelo teste $\mathrm{F}$ para cultivares. 
Tabela 3. Desdobramento da análise de variância para altura de plantas (cm) em função dos períodos de avaliação e métodos de inoculação. UEMS Cassilândia (MS), 2015.

\begin{tabular}{|c|c|c|c|c|c|c|}
\hline \multirow{3}{*}{ Métodos de inoculação } & \multicolumn{6}{|c|}{ Períodos } \\
\hline & & 20 DIAS & \multicolumn{2}{|c|}{40 DIAS } & \multicolumn{2}{|c|}{60 DIAS } \\
\hline & \multicolumn{6}{|c|}{ Altura de plantas $(\mathrm{cm})$} \\
\hline Testemunha & 20,33 & B a & 28,18 & A $\mathrm{a}$ & 31,98 & A a \\
\hline Semente $48 \mathrm{~h}$ & 17,95 & $\mathrm{C} \mathrm{a}$ & 24,91 & $\mathrm{Bab}$ & 30,18 & $\mathrm{~A} a \mathrm{~b}$ \\
\hline Sementes $72 \mathrm{~h}$ & 19,62 & B a & 24,77 & A $a b$ & 26,65 & $\mathrm{~A} \mathrm{abc}$ \\
\hline 9 grãos de arroz & 16,12 & B a & 17,79 & $\mathrm{~B}$ & 24,57 & A \\
\hline C.V.(\%) & \multicolumn{2}{|c|}{30,70} & \multicolumn{2}{|c|}{35,49} & \multicolumn{2}{|c|}{27,18} \\
\hline
\end{tabular}

Médias seguidas de letras minúsculas diferentes na coluna e maiúsculas diferentes na linha, diferem estatisticamente entre si pelo teste de Tukey a $5 \%$ de probabilidade.

Tabela 4. Desdobramento da análise de variância para diâmetro do colo (mm) em função dos períodos de avaliação e métodos de inoculação. UEMS Cassilândia (MS), 2015.

\begin{tabular}{|c|c|c|c|c|c|c|}
\hline \multirow[b]{2}{*}{ Métodos de inoculação } & \multicolumn{6}{|c|}{ Períodos } \\
\hline & \multicolumn{2}{|c|}{20 DIAS } & \multicolumn{2}{|c|}{40 DIAS } & \multicolumn{2}{|c|}{60 DIAS } \\
\hline Testemunha & 2,00 & $\mathrm{Cab}$ & 2,98 & $\mathrm{~B} \mathrm{a}$ & 3,46 & A a \\
\hline Semente $48 \mathrm{~h}$ & 2,01 & $\mathrm{Cab}$ & 2,84 & $\mathrm{~B}$ a & 3,26 & $\mathrm{~A}$ a \\
\hline Sementes $72 \mathrm{~h}$ & 1,78 & $\mathrm{C} \quad \mathrm{b}$ & 2,69 & $\mathrm{~B}$ a b & 3,10 & $\mathrm{~A}$ a \\
\hline 9 grãos de arroz & 1,80 & $\mathrm{~B} a \mathrm{~b}$ & 2,32 & A $b$ & 2,63 & A b \\
\hline C.V.(\%) & \multicolumn{2}{|c|}{29,47} & \multicolumn{2}{|c|}{16,52} & \multicolumn{2}{|c|}{18,89} \\
\hline
\end{tabular}

Médias seguidas de letras minúsculas diferentes na coluna e maiúsculas diferentes na linha, diferem estatisticamente entre si pelo teste de Tukey a $5 \%$ de probabilidade.

Tabela 5. Desdobramento da análise de variância para diâmetro do colo (mm) e número de folhas de plantas de soja em função de cultivares de soja e dos períodos. UEMS Cassilândia (MS), 2015.

\begin{tabular}{|c|c|c|c|c|c|c|c|c|}
\hline \multirow{3}{*}{ Períodos } & \multicolumn{8}{|c|}{ Cultivares } \\
\hline & \multicolumn{2}{|c|}{ NA 7337 RR } & \multicolumn{2}{|c|}{ CD 2737 RR } & \multicolumn{2}{|c|}{ NA 7337 RR } & \multicolumn{2}{|c|}{ CD 2737 RR } \\
\hline & \multicolumn{4}{|c|}{ Diâmetro do colo $(\mathrm{mm})$} & \multicolumn{4}{|c|}{ Número de folhas } \\
\hline 20 dias & 2,20 & $\mathrm{~A} \quad \mathrm{c}$ & 1,82 & B $\quad \mathrm{c}$ & 7,16 & $\mathrm{~A}$ & 7,66 & A c \\
\hline 60 dias & 3,22 & $\mathrm{~A} \mathrm{a}$ & 3,10 & $\mathrm{~B} \mathrm{a}$ & 13,50 & $\mathrm{~B} \mathrm{a}$ & 14,66 & $\mathrm{~A} \mathrm{a}$ \\
\hline C.V.(\%) & \multicolumn{2}{|c|}{28,19} & \multicolumn{2}{|c|}{26,23} & \multicolumn{2}{|c|}{28,57} & \multicolumn{2}{|c|}{28,84} \\
\hline
\end{tabular}

Médias seguidas de letras minúsculas diferentes na coluna e maiúsculas diferentes na linha para cada variável, diferem estatisticamente entre si pelo teste de Tukey a $5 \%$ de probabilidade períodos e pelo teste $\mathrm{F}$ para cultivares.

aumento da incidência de doenças radiculares, entretanto, este resultado não é aplicado para todas as cultivares, apresentando diferença entre as mesmas na intensidade de podridões radiculares.

O diâmetro do colo foi maior para a cultivar NA 7337 RR. Paras as duas cultivares NA 7337 RR e CD 2737 RR o diâmetro do colo apresentou resultados crescentes em relação aos períodos $(20,40$ e 60 dias) (Tabela 5).

Aos 20 e 40 dias o número de folhas das duas cultivares foram semelhantes, no entanto, aos 60 dias a cultivar NA 7337 RR apresentou número de folhas inferior a cultivar CD 2737 RR. As duas cultivares NA 7337 RR e CD 2737 RR apresentaram resultados crescentes para o número de folhas (20, 40 e 60 dias) (Tabela 5).

$\mathrm{Na}$ literatura não existe relato referente à resistência das cultivares
NA 7337 RR e CD 2737 RR perante o patógeno M. phaseolina. No entanto, Woicieckoski \& Costa (25) inocularam Rhizoctonia solani em sementes de cinco cultivares de soja, em que a cultivar NA 7337 RR apresentou severidade de 2,22\% (raízes com lesões entre 2,5 e $5 \mathrm{~mm}$ sem lesões no coleto) em uma escala de 0 a 6 , não diferindo das demais.

Gomes (12) relata que a $M$. phaseolina pode infectar plantas de soja em vários estágios de crescimento, e dependendo do estágio da planta em que a infecção se inicia, vários componentes da produtividade na cultura podem ser afetados. Este fato foi constatado no presente experimento, observa-se que o diâmetro do colo, largura de folhas, comprimento de folhas e número de folhas também foram afetados por M. phaseolina em diferentes períodos de avaliação.

A largura de folhas foi menor na cultivar CD 2737 RR para 
Tabela 6. Desdobramento da análise de variância para comprimento de folhas e largura de folhas em função de cultivares de soja e métodos de inoculação. UEMS Cassilândia (MS), 2015.

\begin{tabular}{|c|c|c|c|c|c|c|c|c|c|c|}
\hline \multirow[b]{2}{*}{ Métodos de inoculação } & \multicolumn{10}{|c|}{ Cultivares } \\
\hline & \multicolumn{3}{|c|}{ NA 7337 RR } & \multicolumn{2}{|c|}{ CD 2737 RR } & \multicolumn{2}{|c|}{ NA 7337 RR } & \multicolumn{3}{|c|}{ CD 2737 RR } \\
\hline & \multicolumn{5}{|c|}{ Comprimento de folhas $(\mathrm{cm})$} & \multicolumn{5}{|c|}{ Largura de folhas $(\mathrm{cm})$} \\
\hline Semente $48 \mathrm{~h}$ & 4,79 & A & & 3,60 & $\mathrm{~B}$ a & 3,37 & $\mathrm{~A} \mathrm{a} \mathrm{b}$ & 3,07 & & \\
\hline Sementes $72 \mathrm{~h}$ & 4,03 & A & & 3,79 & A a & 3,36 & $\mathrm{~A} \mathrm{a} \mathrm{b}$ & 3,14 & B & $\mathrm{a}$ \\
\hline 9 grãos de arroz & 3,59 & $\mathrm{~B}$ & $\mathrm{c}$ & 3,92 & A a & 2,46 & $\mathrm{~A}$ & 2,94 & A & $\mathrm{a}$ \\
\hline C.V.(\%) & \multicolumn{3}{|c|}{19,05} & \multicolumn{2}{|c|}{16,23} & \multicolumn{2}{|c|}{20,24} & \multicolumn{2}{|c|}{20,22} & \\
\hline
\end{tabular}

Médias seguidas de letras minúsculas diferentes na coluna e maiúsculas diferentes na linha para cada variável, diferem estatisticamente entre si pelo teste de Tukey a $5 \%$ de probabilidade para o fator métodos de inoculação e pelo teste $\mathrm{F}$ para cultivares.

Tabela 7. Desdobramento da análise de variância para largura e comprimento de folhas em função de cultivares de soja e períodos. UEMS Cassilândia (MS), 2015.

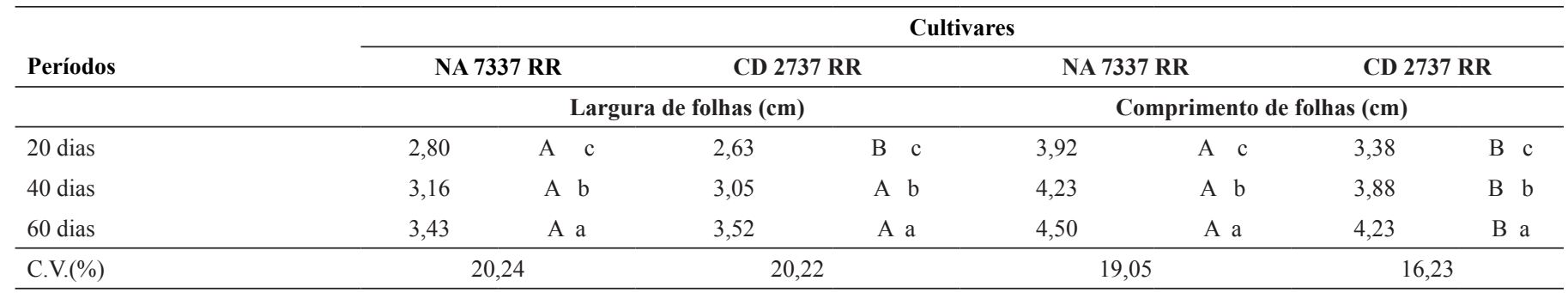

Médias seguidas de letras minúsculas diferentes na coluna e maiúsculas diferentes na linha para cada variável, diferem estatisticamente entre si pelo teste de Tukey a 5\% de probabilidade para períodos e pelo teste $\mathrm{F}$ para cultivares.

testemunha e sementes inoculadas por 72 horas, nos demais tratamentos os resultados foram iguais em ambas as cultivares. A largura de folhas da cultivar NA 7337 RR foi menor no tratamento com nove grãos de arroz, semelhante ao de seis grãos. Para cultivar CD 2737 RR os métodos de inoculação proporcionaram valores igual de largura de folhas (Tabela 6).

Assim como a inoculação de M. phaseolina feita por grãos de arroz propiciou redução nos parâmetros de quantificação indiretos da doença, Klingelfuss et al. (13) também observaram que o fungo $F$. solani f. sp. glycines em soja, inoculado com grãos de milho mostrou-se eficiente e pode ser indicado para avaliações da reação de genótipos de soja à síndrome da morte súbita em casa-de-vegetação.

O comprimento de folhas foi menor para a cultivar NA 7337 RR quando utilizado seis e nove grãos de arroz inoculados com o fungo $M$. phaseolina. E quando utilizado o tratamento de sementes inoculadas por 72 horas, o comprimento de folhas foi semelhante para as duas cultivares. O comprimento de folhas da cultivar NA 7337 RR foi menor com a presença de seis e nove grãos de arroz, que apresentou resultados semelhantes a inoculação de sementes por 72 horas. Contudo, o comprimento de folhas da cultivar CD 2737 RR apresentou valores iguais (Tabela 6).

Lima et al. (15) avaliaram diferentes germoplasmas de feijão caupi, semeados em vasos contendo solo infestado com sementes de crotalária colonizado por M. phaseolina e observaram diferença entre os germoplasmas, sendo que apenas uma amostra foi resistente ao fungo, desta maneira a severidade variou de 20 a $80 \%$. Noronha et al. (21) que trabalharam com 35 genótipos de feijão caupi e apenas a cultivar BRS Pajeú demonstrou ser resistente a M. phaseolina. Esses resultados revelam a dificuldade na obtenção de fontes genéticas com resistência a este patógeno.
A largura de folhas foi menor para cultivar CD 2737 RR aos 20 dias. E o comprimento de folhas foi menor para cultivar CD 2737 RR nos três períodos de avaliações. Para as duas cultivares NA 7337 RR e CD 2737 RR a largura de folhas e o comprimento de folhas apresentaram resultados crescentes (20, 40 e 60 dias) com o passar dos dias após a semeadura (Tabela 7).

De acordo com a tabela 8, observa-se que apenas o tratamento testemunha não apresentou o fungo M. phaseolina e todos os métodos de inoculação empregados proporcionaram o desenvolvimento do fungo nas plantas de soja. Verificou-se também que os primeiros sintomas de podridão de carvão na soja foram observados em plantas inoculadas pelo método diretamente na semente por 48 e 72 horas.

Segundo Medeiros et al. (18), metodologias de infestação de solo com M. phaseolina são menos severa, e exigem maior tempo para aparecimento dos sintomas, uma vez que o patógeno precisa primeiramente se estabelecer no solo para então efetuar a infecção.

Tabela 8. Incidência de $M$. phaseolina em plantas de soja. UEMS Cassilândia (MS), 2015.

\begin{tabular}{ccc}
\hline Métodos de inoculação & \multicolumn{2}{c}{ Cultivares } \\
\hline & NA 7337 RR & CD 2737 RR \\
\cline { 2 - 3 } Testemunha & Ausência & Ausência \\
Semente $48 \mathrm{~h}$ & Presença & Presença \\
Sementes $72 \mathrm{~h}$ & Presença & Presença \\
3 grãos de arroz & Presença & Presença \\
6 grãos de arroz & Presença & Presença \\
9 grãos de arroz & Presença & Presença \\
\hline
\end{tabular}


Contudo, no presente trabalho as metodologias de inoculação naturais testadas e, portanto, que simulam o que ocorre em uma lavoura, demonstram sua aplicabilidade usando estudos, visto que ambas as cultivares apresentaram a doença em todos os métodos de inoculação.

Todos os métodos de inoculação utilizados foram eficientes na inoculação de M. phaseolina em soja. No entanto, o método de inoculação diretamente na semente por 48 e 72 horas, desenvolveu sintomas precoces.

A cultivar NA 7337 RR demostrou ser mais tolerante ao fungo $M$. phaseolina comparado a cultivar CD 2737 RR.

Nos períodos de avaliação os parâmetros de quantificação indireto da doença evoluíram progressivamente aos 20, 40 e 60 dias.

Todos os métodos de inoculação ocasionaram o desenvolvimento do fungo nas plantas de soja.

\section{AGRADECIMENTOS}

À Coordenação de Aperfeiçoamento de Pessoal de Nível Superior - CAPES e à Fundação de Apoio ao Desenvolvimento do Ensino, Ciência e Tecnologia do Estado de Mato Grosso do Sul - FUNDECT, pela concessão da bolsa de pesquisa.

\section{REFERÊNCIAS}

1. Almeida, A.M.R.; Ferreira, L.P.; Yorinori, J.T.; Silva, J.F.V.; Henning, A.A.; Godoy, C.V.; Costamilan, L.M.; Meyer, M.C. Doenças da soja. In: Kimati, H.; Amorin, L.; Rezende, J.A.M.; Bergamin Filho, A.; Camargo, L.E.A. Manual de fitopatologia: doenças das plantas cultivadas. 4.ed. São Paulo: Agronomia Ceres, 2005. cap.64, p.569-588.

2. Barros, R. Doenças na cultura da soja. In: Barros, R. Tecnologia e produção de soja e milho 2008/2009. Maracaju: Fundação MS, 2009. p.109-122.

3. Borges, E.P.; Andrade, D.F.A.A.; Borges, R.A. Doenças da soja e seu controle. In: Borges, E.P. Pesquisa, tecnologia, e produtividade: soja/ milho 2014/2015. Chapadão do Sul: Fundação Chapadão, 2015. cap.11, p.96-108.

4. Câmara, G.M.S.; Heiffig, L.S. Fisiologia, ambiente e rendimento da cultura da soja. In: Câmara, G.M.S. Soja: tecnologia da produção. Piracicaba: ESALQ/LPV, 2000. p. 81-120.

5. Claudino, M.R. Métodos de inoculação de Macrophomina phaseolina em mamoeiro visando à seleção de genótipos resistentes. 2013. 29p. Dissertação (Mestrado em Ciências Agrárias)-Universidade Estadual da Paraíba, Campina Grande.

6. Costa, M.L.N.C; Machado, J.C.; Guimarães, R.M.; Pozza, E.A.; Oride, D. Inoculação de Fusarium oxysporum f. sp. phaseoli em sementes de feijoeiro através de restrição hídrica. Ciência e Agrotecnologia, Lavras, v.27, n.5, p.1023-1030, 2003.

7. Falcão, V.J; Orili, F.P.; Ávila, Z.R.; Mello, S.C.M. Estabelecimento de metodologia para contaminação do solo com propágulos dos fungos Sclerotinia sclerotiorum e Sclerotium rolfsii, e expressão da doença em soja. Brasília, DF: Embrapa, 2005. (Comunicado técnico, 135). Disponível em: $<$ http://ainfo.cnptia.embrapa.br/digital/bitstream/CENARGEN/27926/1/ cot135.pdf $>$. Acesso em: 02 mar 2016

8. Ferreira, D.F. Análises estatísticas por meio do SISVAR para Windows versão 4.0. In: Reunião Anual da Região Brasileira da Sociedade Internacional de Biometria, 45., 2000, São Carlos. Programas e Resumos. São Carlos: UFSCar, 2000. p.235.

9. Franco, H.B.J.; Centurion, M.A.P.C.; Barbosa, J.C. Estudo de métodos de inoculação para avaliação de cultivares de soja a Fusarium tucumaniae. Summa Phytopathologica, Botucatu, v.35, n.1, p.32-38, 2009.

10. Gava, F. Relação entre a população de plantas e a intensidade de doenças da haste e do sistema radicular em soja. 2008. 70p. Dissertação
(Mestrado em programa de pós-graduação em ciências agrárias)-Centro de Ciências Agro veterinárias, Universidade do Estado de Santa Catarina - UDESC, Lages.

11. Godoy, C.V.; Almeida, A. M. R.; Costamilan, L. M.; Meyer M. C.; Dias, W. P.; Seixas, C. D. S.; Soares, R. M.; Henning, A. A.; Yorinori, J. T.; Ferreira, L. P.; Silva, J. F. V. Doenças da soja. In: Amorim, L.; Rezende, J. A. M.; C.; Benjamim Filho, A.; Camargo, L. E. A. Manual de fitopatologia: doenças de plantas cultivadas. Cap. 67. P. 657-676. V.2. Editora Agronômica Ceres Ltda. Ouro Fino-MG. 2016.

12. Gomes, C.J.A. Macrophomina phaseolina em soja, padrão de ocorrência, danos e aspectos físicos, químicos e biológicos do solo relacionados à doença. 2014. 39f. Dissertação (Mestrado em Agronomia)-Universidade Estadual do Norte do Paraná, Bandeirantes.

13. Klingelfuss, L.H.; Yorinori, J.T.; Destro, D. Métodos de inoculação para quantificação de resistência em soja a Fusarium solani f. sp. glycines, em casa-de-vegetação. Fitopatologia Brasileira, Brasília, v.32, n.1, p.50-55, 2007.

14. Lima, L.R.L.; Noronha, M.A.; Silva, K.J.D.; Lopes, A.C.A.; Rocha, M.M. Influência de metodologia de inoculação e da concentração de inoculo de Macrophomina phaseolina no desenvolvimento da podridão cinzenta do caule em feijão caupi. In: Congresso Nacional de feijão-caupi, 3., 2013, Recife. Resumos. Recife: CONAC, 2013. p.1-5.

15. Lima, L.R.L.; Sousa, C.M.B.; Pires, C.J.; Sousa, M.B.; Noronha, M.A.; Lopes, A.C.A.; Silva, K.J.D.; Rocha, M.M. Avaliação de germoplasma de feijão-caupi de porte ereto e semi-ereto para resistência à Macrophomina phaseolina (Tassi) Goid. In: Congresso Brasileiro de Recursos Genéticos, 2., 2012, Belém. Resumos. Belém: CBRG, 2012.

16. Machado, J.C.; Oliveira, J.A.; Vieira, M.G.G.C.; Alves, M.C. Uso de restrição hídrica na inoculação de fungos em sementes de algodoeiro (Gossypium hirsutum). Revista Brasileira de Sementes, Londrina, v.26, n.1, p.62-67. 2004.

17. Machado, C. C. Esporulação de Macrophomina phaseolina (Tass.) Goid. e viabilidade do método de inoculação de esporos em estudos de seleção de germoplasma resistente. Dissertação de mestrado Universidade de São Paulo Escola Superior de Agricultura "Luiz de Queiroz - ESALQ Piracicaba, 1980.66p.

18. Medeiros, A.C.; Melo, D.R.M.; Ambrósio, M.M.Q.; Nunes, G.H.S.; Costa, J.M. Métodos de inoculação de Rhizoctonia solani e Macrophomina phaseolina em meloeiro (Cucumis melo). Summa Phytopathologica, Botucatu, v.41, n.4, p.281-286, 2015.

19. Mengistu, A.; Bond, J.; Nelson, R., Rupe, J.; Shannon, G.; Arelli, P.; and Wrather, A. 2013. Identification of soybean accessions resistant to Macrophomina phaseolina by field screening and laboratory validation. Online. Plant Health Progress. Disponível em: <https://www.plantmanagementnetwork.org/pub/php/research/2013/soybean/>. Acesso em: 05 de agosto de 2017.

20. Noronha, M.A.; Silva, K.J.D.; Gonçalves, S.R.; Lima, L.R.L. Avaliação da resistência de genótipos de feijão-caupi a Macrophomina phaseolina. Aracaju: Embrapa, 2012. (Comunicado técnico, 126).

21. Pires, L. L.; Beserra Junior, J. E. A. Patogenicidade de Macrophomina phaseolina em feijão-fava. Universidade Federal do Piaú. Departamento de fitotecnia. 4 p. Disponível em: < http://sis.ufpi.br/25sic/documentos/ resumos/modalidade/exatas/Lorenna_Leal_Pires.pdf $>$. Acesso em: $14 \mathrm{de}$ agosto de 2017.

22. Souza, N. S. Macrophomina phaseolina, Fusarium falciforme e representantes do complexo Colletotrichum gloepsporioides: novos agentes etiológicos em feijão-fava. Dissertação (mestrado) Programa de pós-graduação em agronomia, produção vegetal. Universidade Estadual do Piauí. Terezina. 2016.

23. Woicieckoski. C. P.; Costa, M. L. N. Severidade de Rhizoctonia solani em cultivares de soja em relação ao potássio. Tecnologia \& Ciência Agropecuária. João Pessoa, v. 10, n. 2, p.22-27, 2016.

24. Wrather, J.A.; Anderson, T.R.; Arsyad, D.M.; GAI, J.; Ploper, D.L.; Porta-Puglia, A.; RAM, H.H.; Yorinori, J.T. Soybean disease loss estimates for the top 10 soybean producing countries in 1994. Plant Disease, v. 81, n. 1, p. 107-110, 1997.

25. Vinholes, P.S. Associação genômica para resistência da soja a Meloidogyne javanica e Macrophomina phaseolina. 2014. 115p. Tese (Doutorado em Fitotecnia)- Universidade Federal de Viçosa, Viçosa. 